\title{
EL ALCANCE DE LA COMPETENCIA EXTERIOR EUROPEA EN MATERIA DE INVERSIONES
}

\author{
LUIS M. HINOJOSA MARTÍNEZ'
}

\author{
Revista de Derecho Comunitario Europeo \\ ISSN-L 1 138-4026, núm. 52, Madrid, septiembre/diciembre (2015), pp. 871-907 \\ http://dx.doi.org/10.18042/cepc/rdce.52.02 \\ Cómo citar/Citation \\ Hinojosa Martínez, L. M. (2015). El alcance de la \\ competencia exterior europea en materia de inversiones. \\ Revista de Derecho Comunitario Europeo, 52, 871-907. \\ doi: http://dx.doi.org/10.18042/cepc/rdce.52.02
}

\section{Resumen}

Este artículo pretende realizar una contribución al debate sobre el alcance de la competencia europea en materia de inversiones, relanzado tras la inclusión de las inversiones extranjeras directas (IED) en la política comercial común (PCC) por el Tratado de Lisboa, y que ha llegado a su punto álgido con la solicitud de la Comisión al Tribunal de Justicia de un Dictamen sobre el Acuerdo de Libre Comercio entre la Unión Europea y Singapur. En este estudio se analizan el origen y el contenido de la competencia europea sobre las inversiones extranjeras directas en el marco de la política comercial común, a la luz de los actos legislativos recientemente adoptados y de la práctica de las instituciones europeas, y se estudian las competencias expresas e implícitas que, en materia de inversiones, se derivan del capítulo sobre movimientos de capital del Tratado de Funcionamiento de la UE. Se exploran así los límites de esta competencia de la UE, cuya irrupción en el derecho internacional de las inversiones está llamada a ser uno de los principales vectores de renovación de este ordenamiento jurídico, en beneficio de una normativa más sensible a la defensa de los intereses generales y de la capacidad legislativa de los Estados.

1 Catedrático de Derecho Internacional Público y Relaciones Internacionales. Universidad de Granada. 


\title{
Palabras clave
}

Competencia exclusiva, compartida, implícita; inversiones; acuerdos internacionales; política comercial común; movimientos de capital.

\section{THE SCOPE OF THE EUROPEAN EXTERNAL COMPETENCE IN THE FIELD OF INVESTMENTS}

\begin{abstract}
This paper aims to make a contribution to the debate on the scope of the European competence on investment. This discussion has been fostered by the inclusion of foreign direct investment in the EU's common commercial policy by the Treaty of Lisbon, and has come to a decisive moment with the Commission requesting an Opinion from the European Court of Justice on the Free Trade Agreement between the European Union and Singapore. In this study, we analyze the origin and content of the European competence on foreign direct investment within the common commercial policy in light of the recently adopted legislation and the practice of the European institutions. We also examine the express and implied powers to regulate investments deriving from the chapter on capital movements of the Treaty on the Functioning of the EU. Thereby, we explore the limits of this EU competence, whose emergence in the international law of investments should become one of the main vectors of renewal of this legal order, fostering international agreements more sensitive to the defense of general interests and of States' legislative capacity.
\end{abstract}

\section{Key words}

Exclusive, shared, implied, competence; European Union; investment; treatymaking power; common commercial policy; capital movements.

\section{LA PORTÉE DE LA COMPÉTENCE DE L'UNION EUROPÉENNE DANS LE DOMAINE DES INVESTISSEMENTS}

\section{Résumé}

Cet article vise à apporter une contribution au débat sur la portée de la compétence européenne relative aux investissements. Cette discussion a été stimulée par l'inclusion de l'investissement direct étranger dans la politique commerciale commune de l'UE par le traité de Lisbonne et elle se trouve dans une phase décisive avec la demande de la Commission à la Cour de justice de l'UE d'un avis sur l'Accord de libre-échange entre l'Union européenne et Singapour. Dans cette étude, nous analysons l'origine et le contenu de la compétence européenne sur l'investissement direct étranger dans la politique commerciale commune à la lumière de la 
législation récemment adoptée et la pratique des institutions européennes. Nous examinons également les pouvoirs explicites et implicites pour réglementer les investissements découlant du chapitre sur les mouvements de capitaux du Traité sur le fonctionnement de l'UE. Ainsi, nous explorons les limites de cette compétence de l'UE, dont l'émergence dans le droit international des investissements devrait devenir l'un des principaux vecteurs de renouvellement de cet ordre juridique, en favorisant des accords internationaux plus sensibles à la défense des intérêts généraux et de la capacité législative des États.

\section{Mots clés}

Compétence implicite, exclusive, partagée; Union européenne; investissement; traités internationaux; politique commerciale commune; mouvements de capitaux. 


\section{SUMARIO}

I. INTRODUCCIÓN. II. LA DEFINICIÓN DE INVERSIÓN EXTRANJERA DIRECTA: 1. El contexto internacional. 2. El Derecho europeo. III. EL CONTENIDO DE LA NOCIÓN DE INVERSIÓN EXTRANJERA DIRECTA EN LOS ARTS. 206 Y 207 DEL TFUE: 1. Un repaso de los precedentes. 2. La inclusión de la inversión extranjera directa en el Tratado de Lisboa. 3. El alcance material de los arts. 206 y 207 del TFUE. 4. Límites de la competencia europea sobre inversiones extranjeras directas en el marco de la política comercial común. IV. LAS COMPETENCIAS BASADAS EN EL CAPÍTULO SOBRE MOVIMIENTOS DE CAPITAL: 1. La competencia implícita de la UE para celebrar acuerdos internacionales. 2. La naturaleza exclusiva o compartida de la competencia. V. LA PARTICIPACIÓN DE LOS EEMM EN LOS ACUERDOS EUROPEOS SOBRE INVERSIONES. VI. CONCLUSIONES.

\section{INTRODUCCIÓN}

El debate sobre el alcance de la competencia europea en materia de inversiones, relanzado tras la inclusión de las inversiones extranjeras directas (IED) en la política comercial común (PCC) por el Tratado de Lisboa, ha llegado a su punto álgido con la solicitud de la Comisión al Tribunal de Justicia de un Dictamen sobre el Acuerdo de Libre Comercio (ALC) entre la Unión Europea y Singapur ${ }^{2}$ que determine cuáles de sus contenidos constituyen competencias exclusivas de la Unión y cuáles competencias compartidas con los Estados miembros (EEMM). Este acuerdo, así como el ALC ya cerrado con Canadá, y otros acuerdos cuya negociación pueda culminar en los próximos meses, seguirán pendientes de ratificación mientras no se resuelva el conflicto competencial.

2 Véanse el Documento de la Comisión C(2014) 8218 final de 30 de octubre de 2014, y la respuesta de la Sra. Malmström en nombre de la Comisión a una pregunta parlamentaria sobre esta cuestión en abril de 2015 (Parlamento Europeo, P-004256/2015, 27 de abril de 2015, disponible en http://www.europarl.europa.eu/ sides/getAllAnswers.do? reference=P-2015-004256\&language=EN). La demanda del que será el Dictamen 2/15 del Tribunal de Justicia de la UE se interpuso el 10 de julio de 2015 y el asunto se encuentra en fase de presentación de observaciones escritas hasta enero de 2016. 
En este trabajo se pretende situar ese debate competencial en su contexto, explorando los límites de la competencia exclusiva de la UE para construir una PCC y para articular de manera coherente las relaciones económicas con los países terceros. Con este objetivo, analizaremos el origen y contenido de la competencia europea sobre IED en el marco de la PCC, a la luz de los actos legislativos recientemente adoptados y de la práctica de las instituciones. También prestaremos especial atención a las competencias expresas e implícitas que, en materia de inversiones, se derivan del capítulo sobre movimientos de capital del Tratado de Funcionamiento de la UE (TFUE).

Este análisis resulta particularmente interesante en el momento presente porque el TJ ha dictado varias sentencias en los últimos años que ayudan a clarificar tanto la definición de los distintos tipos de inversión como la interpretación del art. 3(2) TFUE para la identificación de las competencias europeas externas de naturaleza exclusiva. Nos encontramos así con todos los instrumentos necesarios para avanzar en la delimitación jurídica y conceptual de las relaciones comerciales y financieras de la UE con el exterior, que se configuran como un complejo edificio en permanente construcción y desarrollo.

\section{LA DEFINICIÓN DE INVERSIÓN EXTRANJERA DIRECTA}

En este trabajo se parte de la base de que el contenido de la noción de IED en los principales textos internacionales es similar al significado que se otorga a esta misma expresión en el Derecho europeo. En este sentido, el estudio de esas referencias internacionales puede ayudar a interpretar el concepto de IED en el TFUE.

\section{EL CONTEXTO INTERNACIONAL}

El Código de Liberalización de los Movimientos de Capital de la OCDE, que es el principal instrumento multilateral de liberalización de las transacciones financieras desde 1961, define las inversiones directas como aquellas inversiones realizadas «con el propósito de establecer vínculos económicos duraderos con una empresa como, en particular, las inversiones que otorgan la posibilidad de ejercer una influencia efectiva en la gestión» ${ }^{3}$. Paralelamente, la Definición Marco de la OCDE de Inversión Extranjera Directa se refiere a este mismo concepto como «una categoría de inversión transfronteriza [...] con el objeto de establecer un interés duradero en una empresa residente en

3 OCDE, Código de Liberalización de los Movimientos de Capital, Anexo A, Lista A, 2013. 
una economía diferente de la del inversor directo [con objeto de] garantizar un nivel significativo de influencia por parte del inversor en la gestión de la empresa ${ }^{4}$.

Como puede apreciarse, las definiciones contenidas en los textos de la OCDE contienen dos elementos comunes: a) el establecimiento de una relación duradera, y b) la capacidad para ejercer una influencia efectiva o significativa en la gestión de la empresa. Aún así, la Definición Marco se muestra más concreta, ya que establece que el «interés duradero» se evidencia cuando se adquiere al menos el 10 por ciento del poder de voto en la empresa de la inversión. También es más precisa puesto que incluye en la noción de IED no solo la adquisición o venta de participaciones de capital y la deuda entre empresas, sino también la reinversión de beneficios 5 .

En su Manual sobre Balanza de Pagos, el FMI se remite explícitamente a la noción de IED de la Definición Marco de la OCDE e identifica como tal aquella inversión transfronteriza que permite que un inversor ejerza «el control o un grado significativo de influencia sobre la gestión de una empresa». A pesar de dicha remisión, y matizando versiones anteriores del Manual, el FMI señala que aunque la IED suele implicar «una relación duradera», en algunos casos la relación puede ser "de corta duración» ${ }^{6}$. Junto a las participaciones de capital que entrañan control o influencia en la empresa en la que se invierte, el FMI incluye en el concepto de IED la inversión en empresas relacionadas, ciertos tipos de deuda y las inversiones en sentido contrario (cuando una empresa de inversión presta fondos a su inversor).

En su informe anual sobre las inversiones en el mundo, la UNCTAD identifica regularmente como categorías de IED la compra de participaciones en capital social (incluidas las fusiones y adquisiciones de empresas), los prestamos intra-empresariales y la reinversión de beneficios? ${ }^{7}$.

Este breve repaso de los principales referentes internacionales sobre la noción de IED nos permite apreciar que este concepto tiene un significa-

4 OCDE, OCDE Definición Marco de Inversión Extranjera Directa, 4a edición, Ediciones OCDE, 2008 (editado en castellano en 2011), p. 17. Esta Recomendación del Consejo de la OCDE establece una metodología común para la medición estadística de la IED con objeto de conseguir una armonización internacional de los distintos datos estadísticos nacionales en este contexto.

$5 \quad$ Ibid. p. 27.

6 FMI, Manual de Balanza de Pagos y de Inversión Internacional, 6a edición, 2009, párr. 6.8-6.10, disponible en https://www.imf.org/external/spanish/pubs/ft/ bop/2007/bopman6s.pdf.

7 Conferencia de Naciones Unidas sobre Comercio y Desarrollo, Informe sobre las inversiones en el mundo 2010, p. 11, disponible en http://unctad.org/es/Docs/ wir2010overview_sp.pdf. 
do claro y relativamente uniforme en el contexto jurídico internacional. Se considera que nos hallamos ante una IED cuando se realiza una aportación financiera que proporciona un grado de influencia significativo en la gestión de una empresa situada en otro Estado, con independencia de la forma que adopte dicha contribución.

Sin embargo, la noción de «inversión» es mucho más amplia. Aunque existen muy distintos tipos de acuerdos sobre protección y promoción de las inversiones (APPRIs), y el conjunto de operaciones que protege cada uno de ellos puede variar considerablemente, lo más habitual es que estos cubran un amplio abanico de operaciones económicas como las inversiones de cartera, los derechos de propiedad intelectual, las inversiones inmobiliarias, las concesiones o licencias comerciales, los bienes muebles o las reclamaciones monetarias. En numerosas ocasiones, los Estados parte en el APPRI especifican en el acuerdo cuáles son las «inversiones» protegidas por este ${ }^{8}$. En los casos en los que se utiliza ese término pero no se define su contenido?, la jurisprudencia internacional suele utilizar el test Salini para distinguir las inversiones de otras operaciones económicas. Dicho test exige la presencia de cuatro elementos concurrentes para calificar una transacción como «inversión» ${ }^{10}$ : contribución económica efectiva del inversor, cierta duración del proyecto, asunción de un riesgo operacional y contribución al desarrollo del Estado receptor de la inversión. Aunque esta definición no es aceptada universalmente, y otros laudos arbitrales no consideran necesaria la contribución al desarrollo del Estado ${ }^{11}$, o por el contrario añaden un quinto requisito para constatar la existencia de

$8 \quad$ Resulta frecuente que en los APPRIs concluidos por Estados Unidos, Japón o algunos países europeos se establezca que esos tratados protegen cualquier propiedad que un inversor extranjero posea o controle en el territorio de las partes contratantes (véanse las definiciones más habituales de inversión en los modelos de APPRI que utilizan los países que han concluido un mayor número de este tipo de tratados en las distintas contribuciones que aparecen en Chester BROWN (ed.), Commentaries on Selected Model Investment Treaties, OUP, Oxford, 2013).

$9 \quad$ Como ocurre, por ejemplo, en el art. 25 de la Convención del CIADI.

10 Estos elementos se identificaron en Fedax c. Venezuela, CIADI Asunto ARB/96/3, Decisión sobre jurisdicción de 11 de julio de 1997, publicada en ILM, vol. 37, 1998, p. 1378, fueron confirmados en Salini c. Morocco, CIADI, Asunto núm. ARB/00/4, Decisión sobre jurisdicción de 23 julio de 2001, publicada en ILM, vol. 42, 2003, p. 609, y han sido posteriormente utilizados con frecuencia en la jurisprudencia internacional sobre inversiones.

11 Quiborax c. Bolivia, CIADI Asunto ARB/06/2, Decisión sobre jurisdicción (27 de septiembre de 2012), apartado 222. 
una «inversión» ${ }^{12}$, el núcleo de la mencionada definición disfruta de un considerable consenso ${ }^{13}$.

Por lo tanto, en el contexto jurídico internacional, el concepto de inversión utilizado en la mayoría de los APPRIs incluye la IED, pero suele ir mucho más allá de esta, para abarcar dentro de su ámbito de aplicación una gran variedad de actividades económicas que potencialmente puedan desarrollar los operadores extranjeros.

\section{EL DERECHO EUROPEO}

El art. 63 del TFUE prohíbe «todas las restricciones» en los movimientos de capital entre los EEMM y los países terceros como principio general con muy limitadas excepciones. Los tratados constitutivos no definen la noción de movimiento de capital, pero el TJ ha recurrido en numerosas ocasiones a la Nomenclatura anexa a la ya derogada Directiva $88 / 361 / \mathrm{CEE}^{14}$ para identificar y distinguir las diferentes categorías de movimientos de capital en Derecho europeo, señalando que dicho texto "mantiene un valor indicativo» ${ }^{15}$.

Sin duda alguna, las inversiones directas constituyen una de las transacciones de capital liberalizadas por el art. 63 del TFUE. En primer lugar, aparecen referidas en el primer apartado de la Nomenclatura que acabamos de mencionar. En segundo lugar, y más específicamente, como excepción a la obligación de liberalización del art. 63, el art. 64 del TFUE permite a los EEMM mantener las restricciones sobre las «inversiones directas» aplicables a los países terceros si estas entraron en vigor antes del 31 de diciembre de $1993^{16}$.

12 Phoenix Action, Ltd.c.v República Checa, CIADI Asunto ARB/06/5 39 (15 de abril de 2009), apartado 100, donde también se exigió que la inversión se hubiese realizado de buena fe.

13 Jan Asmus BISCHOFF y Richard HAPP, «The Notion of Investment», en Marc BUNGENBERG, Jorn GRIEBEL, Stephan HOBE y August REINISCH (eds.), International Investment Law, A Handbook, Beck/Hart/Nomos, Munich/Oxford/ Baden-Baden, 2015, p. 495; Alex GRABOWSKI, "The Definition of Investment under the ICSID Convention: A Defense of Salini», Chicago Journal of International Law, vol. 15, 2014, p. 287.

14 Directiva 88/361/CEE del Consejo de 24 de junio de 1988 para la aplicación del art. 67 del Tratado (DO L 178/5, de 8 de julio de 1988).

15 Sentencia Schröder, C-450/09, EU:C:2011:198, apartado 25.

16 Esta cláusula de consolidación se remite al 31 de diciembre de 1999 en los casos de Bulgaria, Estonia y Hungría. 
La liberalización de los movimientos de capital prevista en el art. 63 del TFUE se refiere tanto a las entradas como a las salidas de capital ${ }^{17} \mathrm{y}$, por lo tanto, cuando el Tratado menciona las inversiones directas no puede sino referirse a la IED. El contenido de la noción de inversión directa que aparece en la Nomenclatura de la Directiva 88/361 reproduce la definición de IED recogida en los principales textos jurídicos internacionales ${ }^{18}$.

En este contexto, no parece razonable interpretar que la expresión «inversiones directas» pueda tener un contenido diferente dependiendo de que se utilice en el contexto de la libre circulación de capitales o en el marco de la política comercial común. Ello atentaría contra una elemental coherencia en la interpretación sistemática del TFUE ${ }^{19}$. Bien al contrario, lo más lógico es utilizar la jurisprudencia del TJ sobre la noción de inversión directa (como movimiento de capital) para determinar el alcance de la competencia europea sobre IED en relación con el art. 207 del TFUE, teniendo en cuenta, además, que el TJ utiliza los mismos criterios para identificar cada tipo de movimiento de capital con independencia de que se trate de una operación intracomunitaria o extracomunitaria ${ }^{20}$.

El TJ ha reconocido como IED «cualquier tipo de inversión [...] que sirva para crear o mantener relaciones duraderas y directas entre el proveedor de fondos y la empresa a la que se destinan dichos fondos [y que haga posible] participar de manera efectiva en la gestión o el control de dicha sociedad ${ }^{21}$. Este concepto debe distinguirse de lo que comúnmente se conoce como «inversión de cartera», identificada como la adquisición de títulos en los mercados de capitales "con la única intención de realizar una inversión, pero sin intención de influir en la gestión y el control de la empresa» ${ }^{22}$.

17 Sentencia Santander Asset Management, C-338/11, EU:C:2012:286, apartado 15.

18 Véase el apartado anterior. En su definición de inversiones directas, la Directiva hace referencia expresa al establecimiento de sucursales y filiales, así como a la compra de acciones, los prestamos a largo plazo y la reinversión de beneficios con vistas a «mantener vínculos económicos duraderos».

19 Véase, por ejemplo, la Comunicación de las Comunidades Europeas y sus Estados Miembros al Grupo de Trabajo sobre la Relación entre Comercio e Inversiones de la OMC (por tanto, en el contexto de la PCC) sobre la Definición de Inversión, que recalca la distinción entre IED e inversión de cartera y dibuja una descripción de la IED muy similar a la recogida en el anexo I de la Directiva 88/361 (OMC, WT/ WGTI/W/115 de 16 de abril de 2002, pp. 3-4).

20 Sentencia Haribo Lakritzen, asuntos acumulados C-436/08, C-437/08, EU:C:2009:17, apartados 127-128.

21 Sentencia Test Claimants in the FII Group Litigation, C-446/04, EU:C:2006:774, apartados 181-182.

22 Sentencia Comisión/Portugal, C-171/08, EU:C:2010:412, apartado 49. 
Paralelamente, en su jurisprudencia sobre el alcance del derecho de establecimiento, el TJ ha señalado que sus reglas se aplican a la adquisición de participaciones en una sociedad cuando estas otorgan «una influencia real en las decisiones de la sociedad y [permiten] determinar las actividades de esta» ${ }^{23}$. Como puede apreciarse, las inversiones directas y el derecho de establecimiento se muestran como conceptos paralelos que se solaparán en la mayoría de los casos, aunque no siempre. El abogado general Geldhoed señaló que el test de "participación efectiva» requerido para la IED en el contexto de la libre circulación de capitales, «supone claramente un umbral inferior que el criterio de la «influencia decisiva»» que se exige en el contexto del derecho de establecimiento ${ }^{24}$. El art. 64 del TFUE también distingue entre los movimientos de capital que suponen inversiones directas y los que suponen el establecimiento. De ello se infiere que, a pesar de sus concomitancias, estos dos conceptos no son siempre equivalentes ${ }^{25}$.

Con independencia de lo anterior, puede resultar complejo diferenciar entre inversión directa e inversión de cartera en algunas operaciones financieras. En el mundo de la compraventa de participaciones societarias no existe una clara línea divisoria que permita distinguir matemáticamente estos dos conceptos, ya que la capacidad de influencia en la gestión de una empresa puede variar dependiendo del Derecho nacional aplicable y de lo prescrito en los estatutos de cada sociedad. En función de las circunstancias, una misma participación puede conferir o no la capacidad para controlar la gestión de la

23 Sentencia Baars, C-251/98, EU:C:2000:205, apartado 22.

24 Conclusiones del abogado general Geldhoed Test Claimants in the FII Group Litigation, C-446/04, EU:C:2006:240, punto 119. Véase también el asunto Baars, C-251/98, ya citado, apartado 20, en el que el TJ parece referirse a una "participación sustancial» que podría calificarse como inversión directa pero que no constituye el ejercicio del derecho de establecimiento. Para una interpretación distinta de esta jurisprudencia, puede consultarse Steffen HINDELANG, The Free Movement of Capital and Foreign Direct Investment, OUP, Oxford, 2009, pp. 8388 , que considera que el umbral de influencia necesario para la inversión directa es esencialmente el mismo que para el derecho de establecimiento.

El TJ ha aclarado recientemente los criterios para determinar si una legislación nacional que regula la IED en las relaciones con países terceros debe evaluarse de acuerdo con las disposiciones que rigen el derecho de establecimiento o las que regulan la libre circulación de capitales. En esencia, si la normativa nacional no es aplicable exclusivamente a situaciones en las que la sociedad matriz ejerce una influencia determinante en la sociedad participada, solo pueden aplicarse las reglas relativas a la libre circulación de capitales (las sociedades que se han constituido conforme a la legislación de un país tercero no disfrutan del derecho de establecimiento). Véase la sentencia Kronos, C-47/12, EU:C:2014:2200, apartados 38-39. 
sociedad. Aunque se han establecido umbrales objetivos en otros contextos ${ }^{26}$, estos no parecen compatibles con el criterio cualitativo (el test de influencia efectiva) que emana de la jurisprudencia del TJ. En este marco relativista, se ha sugerido que en los casos más dudosos se deje a los jueces nacionales la calificación de la transacción tras un análisis de las circunstancias específicas ${ }^{27}$.

La Nomenclatura de la Directiva 88/361 proporciona una valiosa guía para identificar la IED en Derecho europeo. Aparte de la creación de sucursales y filiales, califica expresamente como IED las participaciones en empresas, los prestamos a largo plazo y la reinversión de beneficios con vistas a «mantener vínculos económicos duraderos». Las Notas Explicativas de la Nomenclatura señalan que debe considerarse IED «cualquier tipo de inversión» que reúna esta condición y que «este concepto debe entenderse en su sentido más amplio». Por lo tanto, cualquier inversión que permita a un inversor participar efectivamente en la gestión o el control de una empresa, incluso si no le otorga una mayoría de los derechos de voto o del accionariado, tiene que calificarse como inversión directa y no como inversión de cartera ${ }^{28}$. Esta interpretación parece más coherente con el hecho de que un mero prestamo de más de cinco años «a las sociedades en que [se] posee una participación, así como [...] los prestamos vinculados a una participación en los beneficios» deban considerarse inversiones directas ${ }^{29}$.

Como puede apreciarse, la Nomenclatura construye un concepto expansivo de IED. En este sentido, resultaría artificial aceptar una noción amplia de

26 El hecho de que la Definición Marco de IED de la OCDE, antes citada, establezca un umbral del $10 \%$ de la capacidad de voto en la empresa para identificar un parámetro objetivo que permita calificar una operación como inversión directa se explica por la necesidad de fijar una referencia internacional uniforme para la confección de las distintas estadísticas nacionales sobre balanza de pagos. El art. 3(1) de la Directiva 2011/96/UE (DO L 345/8 of 29 de diciembre de 2011) exige el mismo porcentaje de participación en el capital de una empresa para ser considerada sociedad matriz de una filial y beneficiarse de las ventajas fiscales otorgadas por dicha Directiva. Sin embargo, parece evidente que ese porcentaje no garantiza por sí solo y con carácter general una influencia efectiva en la gestión de la empresa.

27 Conclusiones del abogado general Geldhoed Test Claimants in the FII Group Litigation, C-446/04, EU:C:2006:240, punto 30.

28 La configuración del capital de las grandes compañías que cotizan en bolsa (en las que la propiedad de las acciones se encuentra muy dividida) puede permitir una influencia efectiva en la gestión a otra sociedad que posea un porcentaje sustancial pero minoritario del capital, ya sea por sí sola o a través de acuerdos con otros accionistas.

29 Directiva 88/361, anexo I, notas explicativas. 
IED en el contexto del art. 63 del TFUE y propugnar una lectura restrictiva de la misma expresión en el art. 64 del TFUE (o en el art. 207 del TFUE). Como excepción a una de las libertades fundamentales recogidas en el Tratado, la cláusula de consolidación del art. 64 debe interpretarse estrictamente, pero eso no significa que la noción de IED deba "comprimirse» en ese contexto. Entiendo que ello significa, más bien, que el art. 64 no es obstáculo para reconocer el efecto directo de la obligación de liberalización recogida en el art. $63^{30}$, o que la legislación nacional amparada por esta cláusula no puede modificarse sustancialmente después de la fecha de referencia ${ }^{31}$. En el asunto Welte, el TJ ha confirmado que en el contexto del art. 64 hay que utilizar la definición de IED que proporciona la Nomenclatura de la Directiva 88/361, y que las inversiones inmobiliarias que reúnan las características contenidas en dicha definición deben calificarse como inversiones directas ${ }^{32}$.

Conviene añadir que cuando la Nomenclatura se refiere a la IED incluye en este concepto no solo «la terminación y ejecución de la transacción» sino también las «transferencias correspondientes a ella».

En definitiva, como conclusión preliminar, podemos afirmar que la IED se muestra como un concepto relativamente bien definido en Derecho europeo y que este es coherente en lo fundamental con las definiciones del mismo concepto contenidas en los textos jurídicos internacionales más relevantes. Parece igualmente claro que dentro de esa definición comunitaria solo pueden incluirse las transacciones financieras descritas en el apartado I del Anexo I de la Directiva 88/361, con exclusión de las operaciones referidas en los demás apartados del mismo Anexo. En consecuencia, la IED se refiere solo a una parte de las transacciones financieras habitualmente protegidas por muchos de los APPRIs. En particular, la definición de «inversión» que se recoge en el Acuerdo de Libre Comercio entre la Unión Europea y Singapur va mucho más allá de la noción de IED, ya que incluye muchas operaciones de capital clasificadas en otros apartados del mencionado Anexo ${ }^{33}$.

\footnotetext{
30 Sentencia Skatteverket, C-101/05, EU:C:2007:804, apartados 22-27.

31 Sentencia Prunus, C-384/09, EU:C:2011:276, apartados 34-36.

32 Sentencia Welte, C-181/12, EU:C:2013:662, apartados 28-34.

33 El art. 1 del Acuerdo de Libre Comercio entre la Unión Europea y Singapur (pendiente de ratificación) indica que, a los efectos de dicho Acuerdo, inversión significa cualquier tipo de activo que tenga las características de una inversión, incluyendo tanto los activos materiales como inmateriales, bienes muebles e inmuebles, bonos, derivados, derechos de propiedad intelectual, etc. (disponible en http://trade.ec.europa.eu/doclib/docs/2014/october/tradoc_152844.pdf).
} 


\section{EL CONTENIDO DE LA NOCIÓN DE INVERSIÓN EXTRANJERA DIRECTA EN LOS ARTS. 206 Y 207 DEL TFUE}

\section{UN REPASO DE LOS PRECEDENTES}

El estudio de los «trabajos preparatorios» del Tratado de Lisboa y de «las circunstancias de su celebración" proporciona herramientas interesantes para determinar el alcance de los arts. 206 y 207 del TFUE en relación con la IED ${ }^{34}$.

Al tratarse de un tipo de movimiento de capital, la regulación de las inversiones se consideraba una competencia nacional en el primigenio Tratado CEE, por lo que los Estados podían restringir la IED salvo que se estableciese en una Directiva una obligación de liberalización en relación con algún tipo específico de operación ${ }^{35}$. Cualquier medida de armonización del régimen jurídico aplicable a las inversiones procedentes de (o destinadas a) países terceros requería la unanimidad en el Consejo ${ }^{36}$; incluso en la Directiva 88/361 (que prohibió con carácter general las restricciones a los movimientos de capital en el mercado interior), los EEMM mantenían su autonomía para regular las operaciones con los países terceros ${ }^{37}$.

Los EEMM respondieron al espectacular aumento del volumen de IED durante los años ochenta y noventa mediante la articulación de una densa red de APPRIs, que en la actualidad suponen aproximadamente la mitad del número total de APPRIs existentes a nivel mundial y configuran a la UE como el principal actor internacional tanto en la emisión como en la recepción de inversiones.

Cuando se redactó el Tratado de Maastricht, los EEMM y la propia UE ya eran conscientes de la creciente importancia de la IED y de la necesidad de proporcionar seguridad jurídica a las inversiones europeas en terceros países e, igualmente, a las inversiones en la UE procedentes del exterior. La tendencia favorable a la liberalización financiera, que imperaba en el momento en que se negociaba esta importante reforma de los Tratados, llevó a incluir la libre circulación de capitales con los países terceros en el derecho originario. No obstante, el actual art. 64 del TFUE también se introdujo entonces en el capítulo sobre capitales y pagos para intentar hacer compatible esa liberalización con el amplio abanico de APPRIs concluidos por los EEMM y con las disposiciones nacionales que regulaban la IED. Los EEMM pueden mantener su marco

\footnotetext{
$34 \quad$ Art. 32 del Convenio de Viena de 1969 sobre Derecho de los Tratados.

35 Arts.67 y 69 del Tratado CEE.

36 Art. 70 del Tratado CEE.

37 Art. 7 de la Directiva 88/361.
} 
regulador mientras el Consejo y el Parlamento Europeo no adopten medidas que establezcan una regulación europea para las operaciones de capital mencionadas en dicho artículo (incluida la IED), y «sin perjuicio de lo dispuesto en los demás capítulos de los Tratados». Esta última frase puede interpretarse en el sentido de que el art. 64(2) del TFUE solo otorga competencia a las instituciones europeas para adoptar medidas en relación con los movimientos de capital en sentido estricto y, por ende, no constituye una base jurídica adecuada para la regulación de los servicios financieros o del establecimiento en las relaciones con los países terceros ${ }^{38}$. En principio, esa regulación debería encontrar su base jurídica en otros capítulos del Tratado.

Con el paso del tiempo, la Comisión se vio progresivamente implicada en un número creciente de negociaciones sobre textos y acuerdos internacionales que contenían disposiciones sobre inversiones, por la relación tan estrecha que existe entre comercio e inversiones. La práctica comunitaria en los años noventa muestra actuaciones muy diversas y no siempre coherentes a la hora de elegir la base jurídica para la adopción de estos actos ${ }^{39}$. Los acuerdos de asociación que contenían disposiciones sobre IED se concluían sobre la base del antiguo art. 138 del Tratado $\mathrm{CE}^{40}$, aunque al tratarse de acuerdos mixtos eran también ratificados por los EEMM. Más adelante, la UE empezó

$38 \quad$ Una de las primeras propuestas de redacción del entonces art. $73 \mathrm{C}(2)$ del Tratado CE (actual art. 64 del TFUE) era más explícita, pues habilitaba al Consejo a adoptar medidas de coordinación "en ausencia [...] de un régimen comunitario adoptado sobre la base de otros artículos del Tratado» (CONF-UEM 97/91 de 7 de noviembre de 1991). A fortiori, el art. 64(2) habla específicamente de la adopción de «medidas relativas a los movimientos de capitales».

39 La Decisión 94/800/CE (DO L 336/1 de 23 de diciembre de 1994), relativa a la celebración de los acuerdos resultantes de las negociaciones multilaterales de la Ronda Uruguay, entre otras bases jurídicas, hace referencia al antiguo art. 113 del Tratado CE (PCC), pero no menciona los antiguos arts. 73B o 73C del Tratado CE (libre circulación de capitales). Sin embargo, en su Decisión 96/412/ CE (DO L 167/23 de 6 de julio de 1996), que aprobaba el Segundo Protocolo del Acuerdo General sobre el Comercio de Servicios en relación con los servicios financieros, el Consejo hace referencia tanto al antiguo art. 113 del Tratado CE como a los antiguos arts. 73B a 73F del mismo Tratado ( casi todo el capítulo sobre movimientos de capital!), entre otras disposiciones, como bases jurídicas compartidas.

40 Véanse, por ejemplo, la Decisión 93/742/Euratom, CECA, CE relativa a la celebración del Acuerdo de asociación con Hungría (DO L 347/1 de 31 de diciembre de 1993), la Decisión 94/910/CE, CECA, Euratom sobre la conclusión de un Acuerdo de asociación con la República Checa (DO L 360/1 de 31 de diciembre de 1994), o incluso la Decisión 2000/384/CE, CECA relativa a la celebración del Acuerdo euromediterráneo con Israel (DO L 147/1 of 21 de junio de 2000) que 
a utilizar el que hoy es el art. 64(2) del TFUE como base jurídica compartida (junto con los antiguos arts.133 y 308 del Tratado CE) en los acuerdos mixtos de cooperación con disposiciones sobre $\mathrm{IED}^{41}$, incluso cuando se concluyó el Tratado sobre la Carta de la Energía, que abarcaba todo tipo de inversiones y contenía un mecanismo arbitral de solución de controversias inversor-Estado/ Comunidad $^{42}$. Así, por razones prácticas ${ }^{43}$, la Comisión se encontró a menudo negociando cláusulas en materia de IED en el contexto de acuerdos comerciales más amplios y en nombre de todos los EEMM, aunque sin una base jurídica claramente definida ${ }^{44}$.

En tales circunstancias, se entiende que la Comisión intentase reforzar la competencia europea en materia de IED incluyéndola explícitamente en el ámbito de la PCC durante las Conferencias Intergubernamentales que precedieron la adopción tanto del Tratado de Ámsterdam ${ }^{45}$ como del Tratado de $\mathrm{Niza}^{46}$. Sin embargo, en ambos procesos se encontró con la oposición de los

establece la libre circulación de capitales (con algunas excepciones) entre la CE e Israel.

41 Por ejemplo, la Decisión 2001/248/CE (DO L 90/45 de 30 de marzo de 2001) relativa a la conclusión de un Acuerdo de comercio y cooperación con Corea, o la Decisión 2000/684/CE (DO L 283/36 de 9 de noviembre de 2000) relativa a la celebración de un Protocolo del Acuerdo de cooperación con la República de Moldova.

42 Decisión 98/181/CE, CECA, Euratom del Consejo y de la Comisión, de 23 de septiembre de 1997, relativa a la conclusión, por parte de las Comunidades Europeas, del Tratado sobre la Carta de la Energía (DO L 69/1 de 9 marzo de 1998).

43 Meunier ha sintetizado las ventajas que los EEMM obtenían de esa negociación conjunta en los siguientes puntos: facilitación del acceso a los mercados, mayor capacidad de influencia sobre la configuración del escenario internacional y una minoración de los costes generados por la competencia entre los EEMM para atraer inversiones (Sophie MEUNIER, Integration by Stealth: How the European Union Gained Competence over Foreign Direct Investment, Paper presentado en el 7th Annual Conference of the Political Economy of International Organizations, 16-18 de enero 2014, Princeton University, p. 5).

44 Para un comentario de las cláusulas sobre IED en los diferentes acuerdos firmados por la CEE/CE/UE antes del Tratado de Lisboa, así como de las bases jurídicas utilizadas, puede consultarse Luis M. HINOJOSA MARTÍNEZ, «Las relaciones financieras de la UE con el exterior», en Antonio REMIRO BROTÓNS e Irene BLÁZQUEZ NAVARRO (eds.), El futuro de la acción exterior de la Unión Europea, Tirant lo Blanch, Valencia, 2006, pp. 342-349.

45 Doc. CONF 2500/96 de 5 de diciembre de 1996, capítulo 11.

46 Docs. CONFER 4790/00 de 3 de noviembre de 2000 y CONFER 4810/00 de 23 de noviembre de 2000. Véase, al respecto, Stephan GRILLER y Katharina 
EEMM más poderosos, que temían que el complejo conjunto de intereses salvaguardado por sus APPRIs pudiera verse perjudicado por esa centralización de competencias y que no estaban dispuestos a renunciar a una parte significativa de su autonomía en la regulación de las inversiones. Después del fracaso de las negociaciones en la OCDE para la adopción de un Acuerdo Multilateral sobre Inversiones (1995-1999) ${ }^{47}$, en las que estuvieron involucrados tanto la Comisión como los EEMM, la apertura de la Ronda de Doha en la OMC dio un nuevo ímpetu a esta reivindicación.

La Declaración Ministerial de Doha preveía una negociación para el establecimiento de "un marco multilateral destinado a asegurar condiciones transparentes, estables y previsibles para las inversiones transfronterizas a largo plazo, en particular las inversiones extranjeras directas» ${ }^{48}$. El contenido de este Programa de Trabajo era amplio y ambicioso, y parecía desbordar el ámbito de aplicación del actual art. 64(2) del TFUE (que, como ya se ha indicado, se refiere a medidas sobre los movimientos de capital en sentido estricto). El Programa incluía "modalidades de compromisos previos al establecimiento» o mecanismos para la «solución de diferencias» que podían acabar convirtiéndose en los elementos nucleares de un largamente esperado régimen universal regulador de la $\mathrm{IED}^{49}$. Adicionalmente, el comercio de servicios se había incorporado plenamente dentro de la PCC tras el Tratado de Niza, por lo que ciertas inversiones relacionadas con dicho comercio también pasaban a ser competencia exclusiva de la UE. Este escenario planteaba de nuevo, y de una manera más acuciante, la necesidad de incluir en el derecho originario una base jurídica sólida que permitiese a la Comisión representar a todos los EEMM en esta negociación con una sola voz (como venía ocurriendo tradicionalmente en la OMC) y a la UE concluir el correspondiente acuerdo.

GAMHARTER, «External Trade: Is there a Path through the Maze of Competences?», en Stephan GRILLER y Birgit BEIDEL, External Economic Relations and Foreign Policy in the European Union, Springer, Viena, 2002, pp. 90-94; Sophie Meunier, op. cit., nota 43, p. 6.

47 Sol PICCIOTTO, «Linkages in International Investment Regulation: The Antinomies of the Draft Multilateral Agreement on Investment», University of Pennsylvania Journal of International Law, vol. 19, 1998, p. 731. OMC, WT/MIN(01)/DEC/1 de 20 de noviembre de 2001.

49 Las negociaciones debían centrarse en: «alcance y definición; transparencia; no discriminación; modalidades de compromisos previos al establecimiento basados en un enfoque de listas positivas del tipo previsto en el AGCS; disposiciones sobre el desarrollo; excepciones y salvaguardias por razones de balanza de pagos; y celebración de consultas y solución de diferencias entre los Miembros» (OMC, WT/MIN(01)/DEC/1 de 20 de noviembre de 2001, párrafo 22). 
El repaso de estos antecedentes nos lleva a interpretar la inserción de la IED en el marco de la PCC en un sentido amplio, con objeto de habilitar a la UE para negociar y concluir un acuerdo internacional que tratase cualquier cuestión relacionada con la regulación y la protección de la IED.

\section{LA INCLUSIÓN DE LA INVERSIÓN EXTRANJERA DIRECTA EN EL TRATADO DE LISBOA}

El intento inicial (y cohibido) de la Comisión de introducir las inversiones en el ámbito de la PCC en la Convención sobre el Futuro de Europa que elaboró el proyecto de Constitución Europea fracasó, pasando desapercibido ${ }^{50}$. El Informe Final del Grupo VII «Acción Exterior» de la Convención no recogía esta novedad que desapareció en medio de los intensos y complejos debates que tuvieron lugar en ese grupo de trabajo, que tuvo que discutir muchos otros asuntos con más repercusiones mediáticas ${ }^{51}$. A pesar de ello, el Praesidium de la Convención, a propuesta del entonces comisario Michel Barnier, decidió insertar la referencia a la IED en la PCC aparentemente sin debate ${ }^{52}$.

No es descartable que los miembros del Praesidium introdujeran esta modificación sin calibrar adecuadamente todas sus consecuencias. Sin embargo, no puede decirse lo mismo de los debates sobre las enmiendas al proyecto de Constitución que tuvieron lugar en las Sesiones Plenarias de la Convención. Nada menos que 33 enmiendas se referían a la inclusión de la IED dentro del ámbito de la PCC, la mayoría de ellas proponiendo su eliminación y algunas otras, solicitando algún tipo de clarificación ${ }^{53}$. Leídas conjuntamente, estas enmiendas proporcionan una explicación detallada de las posibles con-

$50 \quad$ Intervention de M. Pascal Lamy, membre de la Commission Européenne, lors de la réunion du Groupe de Travail VII, Working Group VII, Working Document 10, 15 de octubre de 2002, pp. 5-6. Lamy defendió la inclusión de «las inversiones» en la PCC para que pudiesen adoptarse decisiones por mayoría cualificada en este ámbito.

51 Me refiero a las nuevas competencias del alto representante para Asuntos Exteriores y de Política de Seguridad, a la creación de un Servicio Europeo de Acción Exterior, a la reforma de la Política Europea de Seguridad y Defensa, etc. Véase el Informe Final del Grupo VII «Acción Exterior», CONV 459/02 de 16 de diciembre de 2002.

52 Sophie Meunier, op. cit., nota 43, p. 9. En su explicación a la Convención, el Praesidium proporcionó una justificación llamativamente simplista señalando que había añadido la referencia a la IED «como reconocimiento del hecho de que los flujos financieros completan el comercio de mercancías y constituyen hoy en día una parte considerable de los intercambios comerciales» (CONV 685/03 de 23 de abril de 2003, p. 52).

53 Véase la lista completa de las enmiendas propuestas en http://european-convention. europa.eu/EN/amendments/amendments3dd9.html?content=866\&lang=EN. 
secuencias que este incremento del catálogo de competencias exclusivas de la UE tendría para la autonomía financiera y normativa de los EEMM. Representantes de los gobiernos francés, alemán e inglés respaldaron la eliminación de la IED del ámbito de la PCC en la sesión plenaria del 4 de julio de 2003, aunque no lograron su propósito ${ }^{54}$. La Conferencia Intergubernamental de junio de 2004, que introdujo algunas modificaciones relevantes en el texto salido de la Convención, no modificó las disposiciones que mencionaban la IED, que pasaron prácticamente desapercibidas ${ }^{55}$. No parece razonable sostener que, a esas alturas, los gobiernos de los EEMM no eran conscientes de la importancia de esa reforma de la PCC.

La única explicación racional de este comportamiento hasta cierto punto indolente de los EEMM es que estos no tenían la intención de renunciar a su competencia para mantener y concluir sus APPRIs ${ }^{56}$ : el uso de la expresión «IED» (un concepto relativamente bien definido en Derecho internacional y europeo), y no del término más amplio «inversiones», indica claramente el limitado alcance de la nueva competencia exclusiva, que se entendía relacionada con las operaciones de establecimiento en el contexto del comercio de bienes y servicios, y que además tenía como objetivo proporcionar una base jurídica sólida para las negociaciones que tenían lugar en ese momento en la $\mathrm{OMC}^{57}$. Si los EEMM renunciaron a un debate de mayor calado sobre este tema se debe a que estos interpretaron que el propio marco de la PCC limitaba por sí solo el alcance de esta nueva competencia.

54 Reacciones al proyecto de texto del documento CONV 802/03, CONV 821/03 de 27 de junio de 2003, Anexo IX, p. 125.

55 A pesar de ello, Portugal solicitó la eliminación de la referencia a la IED en el marco de la PCC, de forma que la regulación europea de las inversiones quedase circunscrita al capítulo sobre movimientos de capital, mientras que Irlanda demandó una definición más clara de IED (CIG 37/03 de 24 de octubre de 2003, párrafo 52).

56 Markus KRAJEWSKI, "The Reform of the Common Commercial Policy», en Andrea BIONDI, Piet EECKHOUT y Stefanie RIPLEY (eds.), EU Law After Lisbon, OUP, Oxford, 2012, pp. 303-304.

57 La conveniencia de consolidar la competencia europea de cara a las negociaciones en la OMC, como uno de los principales argumentos para la inclusión de la IED en la PCC, fue mencionada por algunos representantes gubernamentales, que mostraron su comprensión en este sentido, aunque solicitaron que su limitado alcance se hiciera más explícito (véanse, por ejemplo, los comentarios de Peter Hein, miembro del gobierno británico en la Convención Europea, en su propuesta de enmienda a lo que hoy es el art. 207 del TFUE, disponibles en http://european-convention. europa.eu/docs/Treaty/pdf/866/Art23Hain.pdf). 
Sin embargo, paralelamente, no es posible deducir del contexto descrito que la competencia de la UE se limite a establecer las condiciones de «acceso al mercado", ya que las negociaciones en la OMC no se circunscribían a los compromisos previos al establecimiento, sino que incluían otras cuestiones relativas, por ejemplo, a la protección de los inversores (como la transparencia y la no discriminación) o a la solución de controversias.

Tras el fracaso del proceso de ratificación de la Constitución Europea, los principales contenidos de este instrumento se trasladaron al Tratado de Lisboa sin reabrir el debate de fondo sobre la mayoría de las reformas aportadas por el nuevo texto. En tales circunstancias, no se modificaron los actuales arts. 206 y 207 del TFUE, a pesar de que las negociaciones sobre IED en la OMC se habían cancelado por tiempo indefinido ${ }^{58}$ y de que la doctrina había debatido profusamente sobre las consecuencias de incluir la IED en la PCC 59. Por tanto, me parece infundado asumir que los EEMM no eran plenamente conscientes de lo que estaban haciendo en la Conferencia Intergubernamental de 2007 al adoptar la reforma relativa a la IED.

\section{EL ALCANCE MATERIAL DE LOS ARTS. 206 Y 207 DEL TFUE}

Una interpretación literal de los arts. 206 y 207 del TFUE favorecería una exégesis generosa de la competencia europea sobre IED. En primer lugar, el art. 206 habla de la supresión de las restricciones a «los intercambios internacionales y a las inversiones extranjeras directas» como si se tratase de dos conceptos distintos (que no tienen por qué ir siempre de la mano). En segundo lugar, cuando el art. 207 enumera los contenidos específicos de la PCC, no utiliza la expresión «los aspectos comerciales de» para limitar la competencia sobre IED como sí lo hace con «la propiedad intelectual e industrial». Por tanto, esta interpretación literal permitiría sostener que la UE disfruta de competencia exclusiva para regular todos los tipos de IED en las relaciones con países terceros. Sin embargo, el relato de la negociación del Tratado de Lisboa $^{60}$ y el contexto en el que se sitúan estos artículos (el Título relativo a la PCC) favorecerían una interpretación que limitase la competencia europea a «los aspectos comerciales» de la IED.

A pesar de esta división doctrinal entre quienes sostienen una interpretación restrictiva o, por el contrario, expansiva del alcance de la competencia de

\footnotetext{
58 OMC, WT/L/579 de 2 de agosto de 2004, p. 4.

59 Como muestra de ese debate, véase Markus KRAJEWSKI, «External Trade Law and the Constitution Treaty: Towards a Federal and more Democratic Common Commercial Policy?», CMLRev, vol. 42, 2005, pp. 111-114.

60 Véase el apartado anterior.
} 
la UE en materia de $\mathrm{IDE}^{61}$, considero que las dos posturas no llegan finalmente a resultados muy diferentes en la práctica. La mayoría de las operaciones de IED están relacionadas con el comercio porque confieren al inversor la capacidad (real o potencial) de participar efectivamente en la gestión de una empresa que comercia con bienes o servicios, incluso aunque se trate solo de servicios financieros. La razón por la que se acordó elegir la OMC como el foro apropiado para las negociaciones sobre un acuerdo multilateral sobre IED se encuentra en que se trata de un concepto relacionado con el establecimiento y por tanto con el comercio. En ese contexto, conviene recordar que el acuerdo de la OMC pretendía abarcar todos los tipos de $\operatorname{IED}^{62} \mathrm{y}$, como se ha señalado, esto tuvo mucho que ver con la incorporación de esta nueva competencia al TFUE. En consecuencia, existen argumentos sólidos para sostener que la UE goza de una competencia general para regular la IED con los países terceros en el contexto de un concepto abierto y evolutivo de $\mathrm{PCC}^{63}$.

También se discute en la doctrina si la expresión «supresión progresiva de las restricciones [...] a la IED», que aparece en el art. 206 del TFUE, debe entenderse en el sentido de que la PCC solo puede utilizarse para la adopción de medidas de liberalización y, por tanto, su alcance se limita a la regulación de las condiciones para al establecimiento, o si también incluye en su ámbito de aplicación las medidas postestablecimiento y de protección de los inversores ${ }^{64}$.

61 Para un repaso de este debate, véase KRAJEWSKI (2012), loc. cit., nota 56, pp. 303-304; Jan Asmus BISCHOFF, «Just a Little Bit of «Mixity»? The EU's Role in the Field of International Investment Protection Law», CMLRev, vol. 48, 2011, p. 1527, en p. 1540; Wenhua SHAN y Sheng ZHANG, «The Treaty of Lisbon: Half Way toward a Common Investment Policy», EJIL, vol. 21, 2011, p. 1049, en p. 1060.

62 Véanse los documentos enviados por las Comunidades Europeas y sus EEMM al Grupo de Trabajo sobre la Relación entre Comercio e Inversiones de la OMC, y en particular los docs. WT/WGTI/W/102 de 29 de mayo de 2001 y WT/ WGTI/W/115 de 16 de abril de 2002.

63 Dictamen 1/94 de 15 de noviembre de 1994, Competencia de la Comunidad para celebrar acuerdos internacionales en materia de servicios y de protección de la propiedad intelectual, EU:C:1994:384, apartados 39-41.

64 KRAJEWSKI (2012), loc. cit., nota 56, pp. 302-303; Javier DÍEZ-HOCHLEITNER, «El incierto futuro de los acuerdos bilaterales sobre protección de inversiones celebrados por los Estados Miembros de la UE», Revista Española de Derecho Europeo, núm. 33, 2010, p. 5, en pp. 31-33; Jan CEYSSENS, «Towards a Common Foreign Investment Policy? — Foreign Investment in the European Constitution», Legal Issues of European Integration, vol. 32, 2005, p. 259, en pp. 277-282. 
No obstante, desde mi punto de vista, la evolución de la práctica europea ha inclinado claramente la balanza a favor de la segunda de estas posturas. En primer lugar, será difícil distinguir si una medida debe calificarse como previa o posterior al establecimiento en numerosas ocasiones ${ }^{65}$. El atractivo de un país para un inversor extranjero depende en gran medida de las condiciones jurídicas y económicas tras el establecimiento, y estas circunstancias son siempre analizadas antes de tomar la decisión de entrar en ese mercado. El TJ ha calificado sistemáticamente las restricciones posteriores al establecimiento ${ }^{66}$ que podían «disuadir a los inversores [...] de efectuar tales inversiones» como obstáculos que "condicionan el acceso al mercado", y que resultan por tanto incompatibles con la libre circulación de capitales ${ }^{67}$. En segundo lugar, en el caso de las mercancías, los servicios y los derechos de propiedad intelectual, la PCC también ha incorporado elementos de regulación de los mercados y no solo de acceso a los mercados en sentido estricto ${ }^{68}$. Antes de la reforma de Lisboa, la UE ya gozaba de competencia para adoptar acuerdos en la OMC que regulaban circunstancias posteriores al establecimiento tanto por lo que se refiere a ciertas formas de $\mathrm{IED}^{69}$ como en otros ámbitos. En tercer lugar, prácticamente todos los nuevos APPRIs y acuerdos de libre comercio (ALC) contienen obligaciones posteriores al establecimiento y la competencia de la

65 Por ejemplo, las disposiciones fiscales de un Estado, dependiendo de la perspectiva, podrían calificarse como un incentivo a la IED, un obstáculo a la entrada o una medida posterior al establecimiento.

66 Por ejemplo, el derecho de las autoridades públicas a vetar determinadas decisiones de una empresa o a nombrar directores de manera privilegiada (por encima de los derechos que les otorgaría el volumen de acciones que realmente poseen).

67 Sentencia Comisión/Portugal, C-543/08, EU:C:2010:669, apartado 68.

68 Por ejemplo, el Reglamento (CE) núm. 428/2009 del Consejo, de 5 de mayo de 2009, por el que se establece un régimen comunitario de control de las exportaciones, la transferencia, el corretaje y el tránsito de productos de doble uso (DO L 134/1 de 29 de mayo de 2009). Véanse también los Dictámenes 1/78, EU:C:1979:224, apartado 44, y 1/94, EU:C:1994:384, apartados 59 y 63.

69 El art. XXVIII(d) del GATS indica que la "presencia comercial» comprende la constitución, adquisición o mantenimiento de una persona jurídica, de una sucursal o de oficina de representación; en ese contexto, el TJ había confirmado en su Dictamen 1/2008 (EU:C:2009:739, apartado 119) que la Comunidad, después de la reforma de Niza, también era competente para concluir, en el marco de la PCC, acuerdos internacionales sobre comercio de servicios a cuyo contenido el GATS se refiere como «consumo en el extranjero», «presencia comercial» y «presencia de personas físicas». Esto puede llevar consigo la asunción de obligaciones posteriores al establecimiento, por ejemplo, en relación con las cláusulas de tratamiento nacional o de la nación más favorecida (véase el Dictamen 2/92, EU:C:1995:83, apartados IV.6 y 7). 
UE estaría vaciada de contenido en la práctica si excluyese con carácter general este tipo de disposiciones. Como ya se ha indicado, en las malogradas negociaciones en la OMC para articular un acuerdo sobre IED se incluían obligaciones posteriores al establecimiento y cuestiones relativas a la protección de los inversores.

Por todo lo dicho, parece razonable asumir que las medidas posteriores al establecimiento entran dentro del ámbito de aplicación de la PCC, y que los acuerdos de la UE sobre IED pueden incorporar las cláusulas habituales sobre protección de las inversiones, como el tratamiento nacional, el tratamiento justo y equitativo, la plena protección y seguridad o los mecanismos de solución de controversias inversor-Estado/UE. La práctica posterior a la entrada en vigor del Tratado de Lisboa refuerza esta interpretación cuando, por ejemplo, se especifican mediante un Reglamento los criterios para distribuir entre la UE y los EEMM la responsabilidad financiera que se derive de los litigios inversor-Estado ${ }^{70}$.

En este contexto, creo que el verdadero debate debería centrarse más bien en la determinación de los límites de la PCC en cuanto a la regulación de obligaciones posteriores al establecimiento. En la medida en que la PCC permite tanto la celebración de tratados con terceros países como la adopción de medidas autónomas, la identificación de estos límites tiene una importancia crucial para evaluar el impacto de la nueva competencia exclusiva en la autonomía normativa de los EEMM.

\section{LÍMITES DE LA COMPETENCIA EUROPEA SOBRE INVERSIONES EXTRANJERAS DIRECTAS EN EL MARCO DE LA POLÍTICA COMERCIAL COMÚN}

Se puede identificar un primer límite de fondo que deriva del contexto material en el que se inserta la nueva competencia sobre IED: la PCC. El art. 207 proporciona una base jurídica para regular la IED en las relaciones con países terceros pero no entre los EEMM (esas inversiones intra-comunitarias están reguladas en los capítulos del TFUE relativos a la libre circulación de

70 «Los acuerdos de la Unión deben ofrecer a los inversores extranjeros los mismos niveles de protección [...] que los que ofrecen a los inversores de la Unión el Derecho de la Unión o los principios generales comunes a los sistemas jurídicos de los Estados miembros», considerando 4 del Reglamento (UE) 912/2014 del Parlamento Europeo y del Consejo, de 23 de julio de 2014, por el que se establece un marco para gestionar la responsabilidad financiera relacionada con los tribunales de resolución de litigios entre inversores y Estados establecidos por acuerdos internacionales en los que la Unión Europea sea parte (DO L 257/121 de 28 de agosto de 2014), que tiene el art. 207(2) del TFUE como base jurídica. 
capitales o al derecho de establecimiento), ni menos aún para regular con carácter general los mercados de inversión de los EEMM ${ }^{71}$. Adicionalmente, se pueden identificar numerosos ámbitos de regulación (y competencia) nacional que pueden condicionar o afectar indirectamente al atractivo o la productividad de una inversión (como, por ejemplo, las normas fiscales, laborales o medioambientales). En principio, los EEMM conservan su competencia nacional en estos terrenos ${ }^{72}$, y su capacidad legislativa no se ve afectada, excepto cuando promulgan normas específicamente destinadas a regular la $\mathrm{IED}^{73}$. Este es el sentido en que interpretamos el párrafo sexto del art. 207 del TFUE cuando señala que el ejercicio de las competencias atribuidas por la PCC «no afectará a la delimitación de las competencias entre la Unión y los EEMM ni conllevará una armonización de las disposiciones legales o reglamentarias de los EEMM en la medida en que los Tratados excluyan dicha armonización».

Sin embargo, no puede descartarse que una disposición convencional sobre IED (por ejemplo, garantizando el tratamiento nacional o proporcionando acceso a determinados mecanismos de tutela judicial) tenga repercusiones sobre áreas de competencia nacional. La obligación de los EEMM de respetar el Derecho de la UE cuando ejercen sus competencias nacionales aparece como un principio sólidamente consolidado en la jurisprudencia del $\mathrm{TJ}^{74}$.

Se ha discutido en la doctrina si el art. 345 del TFUE impone un segundo límite material a la competencia europea sobre IED. Esta disposición reserva a los EEMM la regulación del «régimen de la propiedad», lo que les permite, según el TJ, establecer «un régimen de expropiación pública» ${ }^{75}$. Al-

71 Si el art. 114 del TFUE, que permite la armonización de los derechos nacionales con objeto de mejorar el funcionamiento del mercado interior, no atribuye a la UE «una competencia general para regular el mercado interior» (sentencia Alemania/ Parlamento Europeo y Consejo, C-376/98, EU:C:2000:544, apartado 83), parece aún más claro que el art. 206 del TFUE (que simplemente se refiere a la «supresión de las restricciones a la IED») no constituye una base jurídica adecuada para una regulación exhaustiva de los mercados de inversión europeos.

72 Ramón VIDAL PUIG, "The Scope of the New Exclusive Competence of the European Union with regard to Foreign Direct Investment», Legal Issues of Economic Integration, vol. 40, 2013, p. 133, pp. 144-145.

73 El TJ ha señalado que si bien debe realizarse una interpretación «amplia» de la noción de PCC, esto no coloca dentro de su ámbito de aplicación cualquier medida que pueda "afectar a los intercambios comerciales», sino solo aquel acto "dirigido, en lo esencial, a promover, facilitar o regular los intercambios comerciales y [que] produzca efectos directos e inmediatos en el comercio» (sentencia Comisión/ Parlamento Europeo y Consejo, C-411/06, EU:C:2009:518, apartados 70-71).

74 Sentencia Santander Asset Management, C-338/11, EU:C:2012:286, apartado 14.

75 Sentencia Fearon, 182/83, EU:C:1984:335, apartado 7. 
gunos autores deducen de este derecho a expropiar que las limitaciones que habitualmente se establecen en los APPRIs a esta potestad de las autoridades públicas continuarían siendo un ámbito de competencia nacional y, por tanto, quedarían fuera del marco de la $\mathrm{PCC}^{76}$.

El art. 17(1) de la Carta de los Derechos Fundamentales de la UE dispone que «nadie puede ser privado de su propiedad más que por causa de utilidad pública, en los casos y condiciones previstos en la ley y a cambio, en un tiempo razonable, de una justa indemnización por su pérdida». Sin embargo, esta disposición no resuelve por sí sola la duda competencial que acabamos de plantear en el contexto de la PCC. La Carta solo vincula a las instituciones y órganos de la UE, que actúan de acuerdo con el principio de atribución, y aunque también obliga a los EEMM, lo hace «únicamente cuando apliquen el Derecho de la Unión». En consecuencia, la Carta «no amplía el ámbito de aplicación del Derecho de la Unión más allá de las competencias de la Unión, ni crea ninguna competencia o misión nuevas para la Unión» (art. 51 de la Carta).

En estas circunstancias, parece útil recordar que el art. 345 del TFUE constituye una excepción a las libertades fundamentales del Tratado y, como tal, debe interpretarse en sentido estricto ${ }^{77}$. Si bien los EEMM conservan la potestad de decidir cuándo una expropiación es de interés público y de establecer el procedimiento legal para llevarla a cabo, la jurisprudencia del TJ ha identificado numerosos límites a esta competencia derivados del Derecho europeo. Por ejemplo, las expropiaciones y las privatizaciones deben realizarse respetando las libertades fundamentales del Tratado y, en particular, el principio de no discriminación ${ }^{78}$. Además, el art. 345 es compatible con la adopción de medidas de armonización de las normas nacionales que regulan los derechos de propiedad intelectual en la medida en que ello sea necesario para el buen funcionamiento del mercado interior ${ }^{79}$.

Ahora bien, desde mi punto de vista, el argumento más convincente para sostener que la UE goza de competencia para incluir cláusulas sobre expropiación en sus acuerdos sobre IED proviene de la necesidad de dotar de efecto útil al art. 207 del TFUE. Si se tiene en cuenta que las cláusulas sobre expropiaciones constituyen una parte fundamental de la mayoría de los acuer-

76 BISCHOFF, loc. cit., nota 61, p. 1544; CEYSSENS, loc. cit., nota 64, pp. 278-281.

77 Sentencia Santander Asset Management, C-338/11, EU:C:2012:286, apartado 21.

78 Sentencias Comisión/Portugal, C-367/98, EU:C:2002:326, apartado 48, y Fearon, 182/83, EU:C:1984:335, apartado 7.

79 Sentencia España/Consejo, C-350/92, EU:C:1995:237, apartado 22; sentencia del Tribunal de la AELC Surveillance Authority v. Norway, E-2/06 [2007] apartado 79. 
dos sobre IED $^{80}$, otorgar a la UE esta capacidad de celebración de tratados excluyendo dicho elemento esencial carecería de sentido en la práctica ${ }^{81}$. En la medida en que estas cláusulas suelen dejar a los Estados un amplio margen de apreciación para determinar qué tipo de propiedades deben ser públicas o privadas y cuándo resulta de interés público expropiar o privatizar ${ }^{82}$, considero que existen sólidos argumentos para sostener que la inclusión en los acuerdos celebrados en el marco de la PCC de las cláusulas estándar de expropiación (que exigen una justificación de interés general, un proceso equitativo, no discriminación y una compensación adecuada) no conculcaría el derecho de los EEMM a regular el régimen de la propiedad en el sentido del art. 345 del TFUE. Desde la perspectiva de la protección de las inversiones europeas en países terceros, la expropiación de YPF (antigua filial de Repsol en Argentina) en 2012 hizo que algunos EEMM se diesen cuenta de las ventajas de contar en esos casos con una defensa colectiva del conjunto de la Unión.

\section{LAS COMPETENCIAS BASADAS EN EL CAPÍTULO SOBRE MOVIMIENTOS DE CAPITAL}

El capítulo sobre movimientos de capital del TFUE se diseñó con el objetivo primordial de liberalizar los movimientos de capital (tanto entre los EEMM como con los países terceros) con pocas excepciones que permiten establecer restricciones en circunstancias muy específicas. Estas reglas liberales tenían como objetivo consolidar a la UE como un mercado financiero internacional de referencia, que sirviese para respaldar al euro como divisa internacional y para facilitar la financiación de su economía productiva.

80 Véase el art. X.11 del Acuerdo Económico y Comercial Integral entre Canadá y la Unión Europea (CETA-2014, por sus siglas en inglés), disponible en http://trade. ec.europa.eu/doclib/docs/2014/september/tradoc_152806.pdf.

81 El TJ ha mantenido de forma reiterada en su jurisprudencia que las excepciones no pueden interpretarse de manera que priven a las reglas generales de efecto útil (véase, por ejemplo, la sentencia Besora, C-82/12, EU:C:2014:108, apartado 29).

82 Para evitar demandas infundadas de expropiación indirecta, la capacidad de regulación estatal ha sido reforzada en los acuerdos de libre comercio negociados tras la entrada en vigor del Tratado de Lisboa (véase, por ejemplo, el anexo X.11 del CETA, loc. cit., nota 80). Puede consultarse, al respecto, Catharine Titi, «Le “droit de réglementer" et les nouveaux accords de l'Union européenne sur l'investissement», Journal de droit international, núm. 1/2015, p. 534; Ursula KRIEBAUM, «FET and Expropriation in the (Invisible) EU Model BIT», Journal of World Investment and Trade, vol. 15, 2014, p. 454, pp. 465-467. 
El art. 63 del TFUE prohíbe todas las restricciones a los movimientos de capital con países terceros, incluyendo las inversiones tanto directas como de cartera, así como cualquier otro tipo de operación de capital de las habitualmente protegidas por los APPRIs. El contenido y alcance de la noción de «restricción» es el mismo ${ }^{83}$, con independencia de que nos hallemos ante una transacción financiera intracomunitaria o extracomunitaria. Sin embargo, no existe ninguna base jurídica específica en el capítulo sobre movimientos de capital que atribuya a la UE competencia para concluir acuerdos internacionales. Solo se le otorga capacidad normativa de forma expresa en relación con cuatro tipos de operaciones (entre las que se incluye la IED pero no las inversiones de cartera ${ }^{84}$ ) en los párrafos dos y tres del art. 64, que habilitan la adopción de legislación autónoma por parte de la Unión ${ }^{85}$.

El amplio ámbito de aplicación material del art. 63 en las operaciones extracomunitarias le ha permitido a la Comisión defender la idea de que la UE dispondría de poderes implícitos para concluir acuerdos internacionales que abarquen cualquier tipo de inversión, e incluso que esta competencia sería exclusiva en virtud de lo dispuesto en el art. 3(2) del TFUE ${ }^{86}$. De acuerdo con este razonamiento, cualquier acuerdo internacional que contenga disposiciones sobre inversiones de cartera puede afectar a la competencia normativa potencial de la UE sobre la base del art. $63^{87}$. No obstante, mientras que existen convincentes argumentos para justificar la competencia implícita de la UE para celebrar tratados internacionales sobre los movimientos de capital mencionados en el art. 64, su capacidad para celebrar acuerdos internacionales

83 Aunque la noción de restricción sea idéntica, pueden identificarse motivos de interés general que justifiquen restricciones en las relaciones con países terceros que no constituirían una justificación válida de una restricción en los movimientos de capital intracomunitarios (sentencia Haribo Lakritzen, C-436/08, EU:C:2011:61, apartados $109-110$ y 120$)$.

84 Me refiero a las inversiones de cartera que no supongan un establecimiento, la prestación de servicios financieros o la admisión de valores en los mercados de capitales.

85 No es necesario hacer referencia aquí a los poderes normativos otorgados a la UE sobre la base de los arts. 66, 75 y 215 del TFUE, ya que se trata de ámbitos muy específicos que no afectan al discurso que estamos desarrollando aquí.

86 Comunicación de la Comisión «Hacia una política global europea en materia de inversión internacional» COM (2010) 343 final, de 7 de julio de 2010, p. 9.

87 Frank HOFFMEISTER y Günes ÜNÜVAR, «From BITS and Pieces towards European Investment Agreements», en Marc BUNGENBERG, August REINISCH y Christien TIETJE (eds.), EU and Investment Agreements, Nomos Verlag, BadenBaden, 2013, p. 66. 
sobre otros tipos de operaciones de capital es más discutible y, probablemente, sería una competencia compartida con los EEMM.

Para explicar nuestra posición, en primer lugar, debemos distinguir el origen y las características de la competencia normativa de la UE dependiendo del tipo de operaciones de capital de que se trate. Partiendo de esa base, examinaremos si de esa capacidad normativa cabe deducir una competencia implícita para celebrar acuerdos internacionales. Si la respuesta es afirmativa, en segundo lugar, nos preguntaremos si esa competencia implícita sería exclusiva o compartida con los EEMM.

\section{LA COMPETENCIA IMPLÍCITA DE LA UE PARA CELEBRAR ACUERDOS INTERNACIONALES}

Es útil comenzar recordando que el TJ ha confirmado que existen inversiones de cartera que quedan fuera del ámbito de aplicación de la competencia legislativa prevista en el art. 64, apartados 2 y $3^{88}$. Aunque la UE disfruta de una competencia potencial para adoptar legislación que se aplique a todos los tipos de movimiento de capital sobre la base del art. 63 del TFUE (y eventualmente los artículos 114 e incluso 352 del TFUE), esta capacidad apenas se ha utilizado ${ }^{89} \mathrm{y}$, cuando se ha ejercitado, ha debido justificarse de acuerdo con los principios de subsidiariedad y proporcionalidad ${ }^{90}$. Antes de la entrada en vigor de la reforma de Lisboa, el TJ había interpretado de manera consolidada que una cláusula en un APPRI de los EEMM que salvaguardase el derecho de la UE a adoptar medidas restrictivas sobre la base de los arts. 64(2) y (3), 66 y 215 del TFUE respetaría esa potencial capacidad normativa autónoma ${ }^{91}$. Aunque la situación ha cambiado ahora en relación

88 Sentencia Haribo Lakritzen, asuntos acumulados C-436/08, C-437/08, EU:C: 2009:17, apartado 137.

89 Por ejemplo, el Reglamento (CE) 2271/96 del Consejo de 22 de noviembre de 1996 relativo a la protección contra los efectos de la aplicación extraterritorial de la legislación adoptada por un tercer país (DO L 309/1 de 29 de noviembre de 1996). Léase el art. 5 del TUE en relación con el art. 4(2)(a) del TFUE que señala al mercado interior como una competencia compartida.

91 Sentencia Comisión/Austria, C-205/06, EU:C:2009:118, apartado 42. El Considerando 2 del Reglamento (UE) 1219/2012 del Parlamento Europeo y del Consejo, de 12 de diciembre de 2012 , por el que se establecen disposiciones transitorias sobre los acuerdos bilaterales de inversión entre Estados miembros y terceros países (DO L 351/40 de 20 de diciembre de 2012), que señala que las normas del capítulo del TFUE sobre movimientos de capital «pueden verse afectadas por los acuerdos internacionales sobre inversiones extranjeras celebrados por los EEMM» (cursivas nuestras), podría interpretarse en la línea de esta jurisprudencia. 
con la IED por su inclusión en la PCC, la interpretación del capítulo sobre movimientos de capital en lo relativo a las inversiones de cartera, en principio, debería permanecer inalterada.

En este contexto, parece justificado el reconocimiento de una competencia implícita de la UE para celebrar acuerdos internacionales con terceros Estados. Como se ha señalado anteriormente, antes de la entrada en vigor del Tratado de Lisboa, el antiguo art. 57 TCE (actual art. 64 del TFUE) fue utilizado en repetidas ocasiones como una de las bases jurídicas compartidas de las Decisiones adoptadas para la conclusión de acuerdos internacionales comunitarios con cláusulas sobre $\mathrm{IED}^{92}$, salvo en los casos en los que se trataba de un acuerdo de asociación en el que participaban tanto la Comunidad como sus EEMM sobre la base del antiguo art. 310 del TCE ${ }^{93}$. Adicionalmente, en su Decisión 96/412/CE por la que se aprobaba la conclusión del Segundo Protocolo del GATS sobre servicios financieros ${ }^{94}$, el Consejo utilizó entre otras bases jurídicas los antiguos arts. 73B a 73F del TCE (y no simplemente el antiguo art. 73C del TCE). Esta elección resulta muy ilustrativa pues se realizó tras un intenso debate entre la Comisión y el Parlamento Europeo sobre las bases jurídicas más adecuadas ${ }^{95}$, teniendo en cuenta que el acuerdo afectaba a muchos tipos de movimientos de capital más allá de la IED (por ejemplo, la gestión de cartera ${ }^{96}$ ). El Considerando 13 de esta Decisión señala que "en materia de movimientos de capitales [...] en la situación actual del Derecho comunitario, los Estados miembros siguen siendo competentes, dentro del límite definido por las disposiciones del art. $73 \mathrm{C}$ del Tratado». Aunque resulta difícil entender por qué era necesario hacer una referencia a la práctica totalidad de las disposiciones del capítulo sobre movimientos de capital (la mención del antiguo art. 73C TCE hubiera bastado para adoptar medidas sobre cualquier tipo de movimiento de capital que «suponga» la prestación de servicios financieros ${ }^{97} \mathrm{o}$ el

Sobre el citado Reglamento puede consultarse, Antonio PASTOR PALOMAR, «La aplicación práctica del Reglamento (UE) núm. 1219/2012 sobre los acuerdos bilaterales de inversión entre EEMM y terceros países», $R G D E$, núm. 31, 2013. Supra nota 41 .

Supra nota 40.

Decisión 96/412/CE del Consejo de 25 de junio de 1996 relativa a la celebración en nombre de la Comunidad Europea, por lo que respecta a los temas de su competencia, de los acuerdos resultantes de las negociaciones de la Organización Mundial del Comercio sobre servicios financieros y movimiento de personas físicas (DO L 167/23 de 6 de julio de 1996).

Bulletin Quotidien Europe, núm. 3760, 7 de junio de 1996, p. 9.

Decisión 96/412/CE, supra nota 94, p. 36.

Sentencia Wagner-Raith, C-560/13, EU:C:2015:347, apartados 43-44. 
establecimiento), esta Decisión muestra que las competencias implícitas ${ }^{98}$ de la UE sobre movimientos de capital le permiten potencialmente concluir tratados que cubran prácticamente cualquier tipo de transacción financiera. Dicha Decisión confirma igualmente que se trata de una competencia compartida ${ }^{99}$, porque los EEMM «siguen siendo competentes» mientras la UE no adopte una normativa reguladora de esas operaciones de capital («en la situación actual»). Dedicaremos el siguiente epígrafe a explicar con más detalle la naturaleza compartida de esta competencia.

\section{LA NATURALEZA EXCLUSIVA O COMPARTIDA DE LA COMPETENCIA}

Ya hemos señalado que la UE disfruta de competencia para adoptar normas relativas a cualquier tipo de movimiento de capital sobre la base del art. 63 del TFUE. Sin embargo, en ausencia de una legislación europea que regule las inversiones de cartera, un mero poder normativo potencial basado en el art. 63 del TFUE no puede convertir en exclusiva una competencia expresamente calificada por el Tratado como compartida (art. 4(2)(a) del TFUE) ${ }^{100}$. La exclusividad (con algunas limitaciones) de la competencia europea para regular los movimientos de capital con los países terceros ya fue defendida por la Comisión en el asunto C-205/06, y fue tajantemente rechazada por el abogado general Maduro, aunque el TJ no se pronunció sobre la cuestión. Como apuntó Maduro, si una capacidad legislativa meramente potencial impusiera a los EEMM la obligación de abstenerse «de legislar, mediante medidas nacionales o instrumentos internacionales»,

98 Decisión 96/412/CE, supra nota 94, considerando 8.

99 El TJ ya reconoció que puede existir una "competencia implícita compartida» que permita a la UE concluir acuerdos internacionales en su Dictamen 1/03, de 7 de febrero de 2006, Competencia de la Comunidad para celebrar el nuevo Convenio de Lugano, EU:C:2006:81, apartados 114-115 (véanse los comentarios de Steffen HINDELANG y Niklas MAYDELL, "The EU's Common Investment Policy: Connecting the Dots», en Marc BUNGENBERG, Jörn GRIEBEL y Steffen HINDELANG (eds.), International Investment Law and EU Law, Springer, Berlin, 2011, pp. 17-23).

100 Vidal Puig considera que, al prohibir las restricciones sobre los movimientos de capital, el art. 63 armoniza en gran medida la regulación aplicable a las inversiones de cartera (VIDAL PUIG, loc. cit., nota 72, p. 153). Sin embargo, en mi opinión, este razonamiento minusvalora la diferencia entre armonización negativa (la mera prohibición de restricciones) y armonización positiva (la regulación material de las inversiones de cartera) a la hora de fundamentar la existencia de una competencia exclusiva europea. 
cualquier ámbito de competencia compartida podría convertirse en una competencia exclusiva europea ${ }^{101}$.

De manera más explícita, el TJ ha deducido del principio de atribución que una competencia europea solo puede considerarse exclusiva en el sentido del art. 3(2) del TFUE si «el Derecho de la Unión vigente» se ve claramente afectado o alterado por los compromisos internacionales adquiridos en «un ámbito ya cubierto en gran medida por esas normas» ${ }^{102}$. La única excepción a este principio la encontramos en el Dictamen 1/76, en el que el TJ aceptó que una disposición del Tratado podía generar una competencia implícita exclusiva en las relaciones con países terceros aunque la competencia interna no se hubiera ejercitado, si bien posteriormente circunscribió esta posibilidad únicamente a los casos en los que la competencia interna solo pudiese ejercitarse efectivamente al mismo tiempo que la competencia externa, en circunstancias en que no fuese posible alcanzar los objetivos de la UE mediante la adopción de reglas autónomas ${ }^{103}$. Este no es el caso

101 Conclusiones del abogado general Poiares Maduro en el asunto Comisión/Austria, C-205/06, EU:C:2008:391, puntos 23-30. En circunstancias paralelas, el TJ ha indicado que el Acuerdo sobre los Aspectos de los Derechos de Propiedad Intelectual relacionados con el Comercio de la OMC (ADPIC) se encuentra dentro del ámbito de aplicación de la PCC (regula las relaciones con países terceros) y constituye un área de competencia exclusiva de la UE, pero que esto es compatible con la capacidad de la UE para «legislar en materia de derechos de propiedad intelectual e industrial, en virtud de sus competencias en el ámbito del mercado interior», es decir, como competencia compartida que permite armonizar los ordenamientos de los EEMM para mejorar el funcionamiento de dicho mercado interior (Sentencia Daiichi Sankyo, C-414/11, EU:C:2013:520, apartados 55-60). Véase también el Dictamen 1/94, loc. cit., nota 63, apartados 103-105.

Sentencia Comisión/Consejo, C-114/12, EU:C:2014:2151, apartados 70-74. Aunque existe alguna legislación europea relativa a la prestación de servicios financieros que incide sobre algunos tipos de inversiones de cartera (por ejemplo, la Directiva 2001/34/CE del Parlamento Europeo y del Consejo, de 28 de mayo de 2001, sobre la admisión de valores negociables a cotización oficial, DO L 184/1 de 6 de julio de 2001), en el estado actual del Derecho europeo no es posible sostener que las inversiones de cartera constituyen un ámbito "cubierto en gran medida» por el ordenamiento comunitario, tal y como exige la jurisprudencia del TJ. En esta línea, el TJ ha establecido que "la naturaleza de las disposiciones mínimas [los APPRIs suelen establecer estándares básicos muy generales] contenidas tanto en las normas comunitarias como en las disposiciones del acuerdo internacional puede dar lugar a la conclusión de que no existe afectación, aunque las normas comunitarias y las disposiciones del acuerdo cubran el mismo ámbito» (Dictamen 1/03, supra nota 99, apartado 127).

103 Dictamen 1/76 de 26 de abril de 1977, EU:C:1977:63, apartado 4; Dictamen 1/94, supra nota 63, apartado 89. Véase, al respecto, Federico ORTINO y Piet 
de las inversiones de cartera (o de otros movimientos de capital habitualmente protegidos en los APPRIs), ya que no parece haber ningún motivo que impida a la UE la adopción de legislación autónoma en este terreno, si así se considera conveniente de acuerdo con los principios de subsidiariedad y proporcionalidad.

En la misma línea, las competencias normativas nacionales reconocidas por el art. 65 del TFUE también hablan a favor de una competencia compartida. Adicionalmente, los acuerdos mixtos facilitarían la inserción de cláusulas sobre derecho laboral, protección medioambiental o incluso derecho fiscal.

El Reglamento 912/2014 $4^{104}$ también contiene varias afirmaciones que apuntan hacia una competencia compartida para la conclusión de los APPRIs europeos. Su base jurídica —el art. 207 del TFUE— y su considerando 1 confirman que cualquier competencia atribuida por dicho Reglamento debe situarse en el contexto de la PCC y se refiere por tanto a la IED (véase también el art. 2(a) del Reglamento). El considerando 3 señala que la responsabilidad internacional derivada de los APPRIs «se determina en función del reparto de competencias entre la Unión y los Estados miembros». El art. 1 reconoce que pueden celebrarse APPRIs en los que sean parte tanto la Unión como sus EEMM. Finalmente, una Declaración conjunta del Parlamento Europeo, el Consejo y la Comisión anexa al Reglamento aclara que este «no podrá interpretarse como un ejercicio de las competencias compartidas de la Unión en ámbitos en los que la competencia de la Unión no se haya ejercido». Esto impide a la Comisión utilizar el mencionado Reglamento como un ejemplo de legislación europea que afecta a las inversiones de cartera, que a su vez le permitiese alegar en el futuro el principio de ocupación del terreno ${ }^{105}$ y justificar la aplicación del art. 3(2) del TFUE.

Los problemas que puedan generarse en la gestión de los acuerdos mixtos con cláusulas sobre inversiones, así como la necesidad de proporcionar seguridad jurídica a las partes contratantes en dichos acuerdos ${ }^{106}$, no afectan a

EECKHOUT, «Towards an EU Policy on Foreign Direct Investment», en Andrea BIONDI, Piet EECKHOUT y Stefanie RIPLEY (eds.), EU Law After Lisbon, OUP, Oxford, 2012, p. 312, pp. 317-318.

104 Supra nota 70. Véanse al respecto Francisco PASCUAL VIVES, «La responsabilidad financiera y la participación en el arbitraje de inversiones de la UE y sus EEMM a la luz del Reglamento (UE) núm. 912/2014», e Íñigo IRURETAGOIENA AGUIRREZABALAGA, «Responsabilidad financiera resultante de los arbitrajes de inversión constituidos sobre la base de los futuros acuerdos de inversión de la UE», ambos publicados en la REDI, vol. 67, núm. 1, 2015, pp. 294 y 335 respectivamente. 105 Art. 2(2) del TFUE.

106 Francisco PASCUAL VIVES, «Shaping the EU Investment Regime: Choice of Forum and Applicable Law in the International Investment Agreements», Cuadernos de Derecho Transnacional, vol. 6, núm. 1, 2014, p. 269. 
la distribución de competencias entre la UE y sus EEMM, que debe determinarse en función de las bases jurídicas recogidas en el Derecho de la Unión ${ }^{107}$.

A pesar de todo lo dicho, la Comisión quizá podría encontrar algún argumento para intentar justificar la naturaleza exclusiva de la competencia europea para concluir acuerdos sobre inversiones en uno de los criterios recientemente establecidos por el TJ para determinar si un área ya está cubierta en gran medida por las normas europeas: la necesidad de tener en cuenta «no solo el estado actual del Derecho comunitario en el ámbito de que se trata, sino también sus perspectivas de evolución, cuando estas son previsibles» ${ }^{108}$. En los ALC que se están negociando en la actualidad, es la Comisión quien representa a los EEMM, y de esta práctica puede surgir un cierto modelo europeo de APPRI o de capítulo sobre inversiones en los ALC ${ }^{109}$. En ese contexto, no se puede descartar que la interpretación/aplicación autónoma de una disposición sobre inversiones de cartera en un tratado europeo por parte de un EM afecte a normas comunes, en el sentido de que condicione los derechos y obligaciones de los demás EEMM en ese o en otro acuerdo, o de que perjudique la uniforme aplicación del Derecho europeo. Estas circunstancias podrían atraer esos actos dentro del ámbito de las competencias exclusivas en la línea del art. 3(2) del TFUE ${ }^{110}$. En cualquier caso, como ya se ha señalado

107 Dictamen 1/08 de 30 de noviembre de 2009, sobre el Acuerdo General sobre el Comercio de Servicios (AGCS) - Listas de compromisos específicos, EU:C:2009:739, apartado 127. Para un examen de los complejos problemas que plantea la celebración de los APPRIs como acuerdos mixtos en relación con la atribución de responsabilidades, puede consultarse Angelos DIMOPOULOS, «The Involvement of the EU in Investor-State Dispute Settlement: A Question of Responsibilities», CMLRev, vol. 51, 2014, p. 1671.

108 Sentencia Green Network, C-66/13, EU:C:2014:2399, apartado 61. Véanse, al respecto, los comentarios de Allan ROSAS, «EU External Relations: Exclusive Competence Revisited», Fordham International Law Journal, vol. 38, 2015, p. 1073, en pp. 1093-1094, y Diego J. LIÑÁN NOGUERAS, «La acción exterior de la Unión: las relaciones exteriores (I)», en Araceli MANGAS y Diego J. LIÑÁN NOGUERAS, Instituciones y Derecho de la Unión Europea, Tecnos, Madrid, 2014, pp. 536-537. August REINISCH, «Putting the Pieces together ... an EU Model BIT?», Journal of World Investment and Trade, vol. 15, 2014, p. 679.

110 En un sentido similar, véanse el Dictamen $1 / 13$ de 14 de octubre de 2014 sobre el Convenio sobre los aspectos civiles de la sustracción internacional de menores, EU:C:2014:2303, apartado 89, y los comentarios de Andrés DELGADO CASTELEIRO, "On the Scope of EU's Exclusive Competence after the Lisbon Treaty», RDCE, núm. 51, 2015, p. 669, en pp. 679-681. En el mismo sentido, el Dictamen $1 / 03$, supra nota 99 , apartado 131 , ha relativizado en cierta medida las limitaciones derivadas de la base jurídica de un acto a la hora de determinar si esas normas comunes europeas se ven afectadas por un acuerdo internacional. 
anteriormente, este argumento basado en la afectación de normas comunes podría tener más oportunidades de éxito ante el TJ en el futuro que en el estado actual del Derecho europeo, debido a la escasez de normas comunitarias que regulen las inversiones de cartera. Además, conviene recordar que, con carácter general, una competencia que es compartida antes de la celebración de un tratado internacional sobre esa materia continúa siéndolo después de la conclusión del mismo ${ }^{111}$.

\section{LA PARTICIPACIÓN DE LOS EEMM EN LOS ACUERDOS EUROPEOS SOBRE INVERSIONES}

Aun en el caso de que se que se admita que la competencia para concluir APPRIs/ALC que cubran todo tipo de inversiones es probablemente compartida entre la UE y sus EEMM, todavía queda por determinar qué papel deben jugar estos en dichos acuerdos.

Algunos autores señalan que esta competencia implícita compartida permitiría a la UE concluir sus propios APPRIs/ALC, que cubriesen también las inversiones de cartera, sin necesidad de participación de los EEMM ${ }^{112}$. El principal argumento en el que se apoya esta teoría parte de considerar que, desde un punto de vista material, el Derecho europeo se solapa con los contenidos habituales de los APPRIs ${ }^{113}$. Cuestiones habitualmente tratadas en los APPRIs

111 Eleftheria NEFRAMI, "Mixed Agreements as a Source of European Union Law», en Enzo CANNIZZARO, Paolo PALCHETTI y Ramses WESSEL (eds.), International Law as Law of the European Union, Martinus Nijhoff, Dordrecht, 2012, p. 325, pp. 331-338.

112 HINDELANG y MAYDELL, loc. cit., nota 99, pp. 23-26; VIDAL PUIG, loc. cit., nota 72, p. 161. Esta parece también ser la postura de principio de A. Hervé, aunque posteriormente señala que el amplísimo ámbito de aplicación de los ALC recientemente negociados y la necesidad de asegurar la competencia de los órganos arbitrales en relación con los EEMM pueden terminar obligando a celebrar acuerdos mixtos (Alan HERVÉ, «L'Union européenne comme acteur émergent du droit des investissements étrangers: pour le meilleur ou pour le pire?», Cahiers de droit européen, vol. LI, núm. 1, 2015, p. 179, pp. 185-188).

Véase el considerando 2 del Reglamento (UE) 1219/2012 (supra nota 91) y, paralelamente, el debate sobre la compatibilidad entre los APPRIs intracomunitarios y el Derecho Europeo (Philip STRIK, Shaping the Single European Market in the Field of Foreign Direct Investment, Hart Pub., Oxford, 2014, pp. 187 y siguientes; Francisco José PASCUAL VIVES, «Los acuerdos sobre promoción y protección recíproca de las inversiones extranjeras y el Derecho de la Unión Europea», Revista Española de Derecho Europeo, núm. 40, 2011, p. 441, pp. 450-464; Angelos 
como la prohibición de discriminaciones, el tratamiento nacional, el derecho a un proceso justo o las ayudas de Estado, también están reguladas por el Derecho europeo y se aplican a las inversiones de cartera ( $\mathrm{y}$ a todo tipo de movimientos de capital). El paralelismo entre competencias internas y competencias externas, junto con la necesidad de garantizar la aplicación efectiva y uniforme del Derecho europeo, justificarían que la UE concluyese estos tratados por sí sola.

Sin embargo, a pesar de las concomitancias que acaban de mencionarse, parece necesario reconocer que algunos de los contenidos materiales y procesales de los APPRIs no están regulados por el Derecho europeo, que numerosos APPRIs proporcionan una protección más eficaz para los inversores ${ }^{114}$ $y$, en particular, que las inversiones de cartera no constituyen un ámbito «ya cubierto en gran medida" por las normas europeas. En principio, una competencia implícita externa que tiene su origen en una competencia interna compartida debería dar lugar a la conclusión de un acuerdo mixto con la participación de los EEMM ${ }^{115}$. En esas circunstancias, los EEMM podrían autorizar a la UE a negociar todos los contenidos del acuerdo y a concluirlo en solitario. Cuando la competencia para concluir un acuerdo es compartida, las negociaciones entre los EEMM y las instituciones europeas para decidir cuál será la representación de la UE a veces conducen a complejos pactos y las decisiones se toman caso por caso ${ }^{116}$.

De todas formas, varios EEMM han mantenido hasta ahora la postura de no autorizar la firma en solitario de acuerdos por parte de la UE en ámbitos en los que la competencia europea no se había ejercido previamente ${ }^{117}$.

DIMOPOULOS, «The Validity and Applicability of International Investment Agreements between EU Member States under EU and International Law», CMLRev, vol. 48, 2011, p. 63).

José Carlos FERNÁNDEZ ROZAS, «Conjeturas en torno a la nueva política global europea en materia de inversión internacional tras el Reglamento núm. 912/2014", La Ley Unión Europea, núm. 18, septiembre, 2014, pp. 1-36, en p. 9. Dictamen 1/94, supra nota 63, apartados 104-105.

Kati KULOVESI y Marise CREMONA, «The Evolution of EU Competences in the Field of External Relations and its Impact on Environmental Governance Policies», en Christine BAKKER y Francesco FRANCIONI (eds.), The EU, the US and the Global Climate Governance, Ashgate, Dorchester, 2014, p. 81; Geert DE BAERE, Constitutional Principles of EU External Relations, OUP, Oxford, 2008, pp. 238-241.

Ricardo GOSALBO BONO, «Insuficiencias jurídicas e institucionales de la acción exterior de la UE», $R D C E$, núm. 50, 2015, p. 231, pp. 248-251, H. M. GOVERNMENT, Review of the Balance of Competences between the United Kingdom and the European Union, Trade and Investment, febrero 2014, párrafo 2.13, disponible en https://www.gov.uk/government/uploads/system/uploads/attachment_data/file/ 
Además, si tenemos en cuenta la actitud beligerante que algunos de ellos han mostrado frente a la pretensión de la Comisión de reclamar los APPRIs como una competencia exclusiva de la UE, parece poco probable que en el futuro inmediato los EEMM decidan renunciar unánimemente a su capacidad para celebrar los APPRIs junto con la UE (a no ser que sean obligados a hacerlo por el TJ). Ello resulta compatible con la práctica actual de autorizar a la Comisión para negociar los APPRIs/ALC en nombre de la UE y de los EEMM mediante un procedimiento de doble autorización ${ }^{118}$.

Por tanto, en principio, la celebración de un acuerdo mixto implica que todos los EEMM deban ratificarlo para que este entre en vigor ${ }^{119}$. Eso significa que tienen que ponerse en marcha los correspondientes procedimientos constitucionales en cada EM, incluyendo todos los mecanismos de control allí previstos por parte de los parlamentos nacionales y, en su caso, de los tribunales constitucionales. Lógicamente, ese proceso puede retrasar de manera considerable la entrada en vigor de estos acuerdos.

\section{CONCLUSIONES}

En este artículo se ha intentado contribuir a aclarar el alcance de la competencia europea para celebrar APPRIs o ALC con amplios capítulos sobre inversiones. Para ello, este trabajo se ha centrado en el análisis del capítulo sobre movimientos de capital del TFUE y de la redacción de las nuevas normas adoptadas en el marco de la PCC tras el Tratado de Lisboa, a la luz de la práctica comunitaria más reciente en la negociación de ALC y del examen de la jurisprudencia del TJ sobre las nociones de competencia implícita y compe-

279322/bis_14_591_balance_of_competences_review_Trade_and_investment_ government_response_to_the_call_for_evidence.pdf.

Para evitar que los debates sobre competencias retrasasen las negociaciones de los distintos acuerdos, desde que se iniciaron las conversaciones con Japón en 2012 para la celebración de un ALC, es práctica habitual que el Consejo otorgue a la Comisión un mandato de negociación en los ámbitos de competencia europea, mientras que los EEMM autorizan de manera independiente a la Comisión a negociar en su nombre en las áreas de competencia nacional. Esto proporciona más tiempo para desenmarañar el conflicto competencial, pero no resuelve el problema.

119 Alternativamente, se puede prever la aplicación provisional del acuerdo en aquellos ámbitos de competencia exclusiva de la UE o para los EEMM que ya lo hayan ratificado (Nikos LAVRANOS, «The Remaining Decisive Role of Member States in Negotiating and Concluding EU Investment Agreements», en Marc BUNGENBERG, August REINISCH y Christien TIETJE (eds.), EU and Investment Agreements, Nomos Verlag, Baden-Baden, 2013, p. 165). 
tencia exclusiva/compartida. Esta investigación nos ha llevado a la conclusión de que la UE disfruta de una competencia exclusiva para concluir tratados internacionales sobre IED, incluso si estos albergan compromisos posteriores al establecimiento y contienen las típicas cláusulas sobre protección de inversiones, como la de tratamiento nacional, trato justo y equitativo, plena protección y seguridad y mecanismos de solución de controversias inversor-Estado/ UE. Igualmente, creemos que la UE goza de competencia para incluir en esos acuerdos las cláusulas estándar sobre expropiaciones que exigen una justificación de interés general, un proceso equitativo, no discriminación y una compensación adecuada.

Por otro lado, consideramos que la UE solo posee una competencia implícita y compartida para celebrar APPRIs/ALC que extiendan su ámbito de cobertura a todo tipo de transacciones financieras (incluidas las inversiones de cartera) y que esos tratados deben concluirse como acuerdos mixtos, con la participación de todos los EEMM, salvo que estos decidan libremente delegar su competencia convencional en determinadas circunstancias.

En este contexto se generan serios problemas de seguridad jurídica y de atribución de responsabilidades, que no han sido completamente resueltos por el Reglamento 912/2014 ${ }^{120}$. Por motivos prácticos y para reforzar el poder negociador europeo, la Comisión se ha situado en los últimos años como negociador único en representación de la UE y de sus EEMM en varios APPRIs/ ALC, como ocurría en la OMC en los tiempos en que los servicios y los derechos de propiedad intelectual aparecían como competencias compartidas. El debate competencial en materia de inversiones probablemente evolucionará en el mismo sentido que con los servicios y los derechos de propiedad intelectual, en la medida en que se consolide la experiencia de la Comisión en la negociación de acuerdos y en la solución de controversias sobre inversiones. En un futuro mediato, se debería otorgar a la UE una competencia expresa para concluir sus propios APPRIs/ALC que abarcasen todo tipo de transacciones financieras (posiblemente con alguna salvaguardia que preservase la competencia nacional para regular determinadas cuestiones relativas a los mercados nacionales de capital). Abrimos así la puerta a un nuevo debate para dilucidar si sería mejor afrontar esta reforma incluyendo todos los tipos de inversión en la PCC o mediante una nueva base jurídica en el capítulo sobre movimientos de capital.

120 Supra nota 70. Sin embargo, estos problemas no deben exagerarse (Christophe HILLION, «Mixity and Coherence in EU External Relations: The Significance of the Duty of Cooperation", in Christophe HILLION y Panos KOUTRAKOS (eds.), Mixed Agreements Revisited - The EU and its Member States in the World, Hart Pub., Oxford, 2010, p. 87. 
El primer paso en esta evolución debe ser el esperado Dictamen 2/15 del TJ sobre el ALC entre la UE y Singapur. De todas formas, se tardará muchos años, incluso décadas, en sustituir la densa red de APPRIs de los EEMM por acuerdos europeos. Tras resolver su dilema competencial interno, la UE tendrá que afrontar la previsible oposición de algunos países terceros para renegociar sus APPRIs preexistentes con un nuevo socio que goza de más poder negociador. A pesar de ello, la UE debe actuar con determinación en este ámbito, pues está llamada a ser uno de los principales actores en la reforma del Derecho internacional de las inversiones, en el que tendría que promover la aparición de una nueva generación de APPRIs/ALC que favorezcan la defensa del interés general y eviten que elementos esenciales del modelo político y social europeo puedan verse cuestionados en mecanismos arbitrales de solución de controversias entre inversores y Estados ${ }^{121}$.

121 La Comisión se muestra consciente de la necesidad de promover la reforma del Derecho internacional de las inversiones y declara su voluntad decidida de colocar a la UE en la vanguardia de ese proceso. En este sentido, destaca su propuesta de crear un Tribunal internacional permanente para la solución de controversias sobre inversiones, que podría inspirarse en el sistema público y permanente de solución de controversias que se está negociando en el marco del Tratado Transatlántico de Comercio e Inversiones (TTIP, en sus siglas en inglés) entre la UE y Estados Unidos (Comunicación de la Comisión «Trade for all. Towards a More Responsible Trade and Investment Policy», octubre de 2015, pp. 21-22, disponible en http://trade. ec.europa.eu/doclib/docs/2015/october/tradoc_153846.pdf). 
